\title{
Capitalization on Catalog Cards: Brief Guidelines
}

\section{by Louise Deshaies \\ Head, Descriptive-Adaptive Cataloging Section \\ Louis Round Wilson Library University of North Carolina at Chapel Hill}

Anyone who is responsible for descriplive cataloging and who likes to feel that such description is in correct form encounters the problem of capitalization. Which words should be capitalized? How can one know all languages and their rules for capitalization? How can one teach another so that he will not have to ask about every book in a foreign language for which he must type a master?

The following solutions for proper capitalization have been suggested: 1 . Let the cataloger underscore the words which should be capitalized; 2. Refer to the Anglo-American Catalog Code appendix dealing with capitalization or to a foreign anguage manual; 3 . Use all capitals in typing the master; and 4. Let someone who knows mark all the books before typing.

Objections to these solutions follow respectively. 1. This is not the job of the cataloger; the cataloger may forget to $d_{0}$ it; and the cataloger often does not know. 2. It is too much trouble; only the most conscientious and intelligently aggressive worker will continue to refer to manuals and other tools or wade through explanations. 3. This has been tried and found to be more trouble and time consuming than regular habitual typing. There has to be shifting from upper to lower case because of diacritical marks and numerals; and often the typist unconsciously drops back into the regular way of typing. And 4. A person with an extensive knowledge of languages will usually be occupied primarily with other duties, very likely supervisory, which leaves little time for marking books; and marking books takes time. Needless to say, there are few per- sons available with a knowledge of many languages.

With these things in mind, the following table has been made as another answer to the problem of capitalization, or at least a help. Similarities in languages are evident to those who have studied several and who work with them constantly. One of these similarities is capitalization. Languages, in general, fall into two groups as far as capitalization is concerned. There are those with much capitalization, as English, and there are those with little capitalization, as French. English as the native language in American libraries offers little difficulty, although it has its problems. French is quite often the foreign language which workers have studied.

Using these two languages as familiar languages, other languages are grouped with them to provide the two groups given in the table. Types of words most usually encountered on catalog cards are indicated in the columns. Under these is the indication for capitalization. At the bottom of the table appear a few other helps.

Very few library workers, professional as well as non-professional, have a knowledge of more than two or three foreign languages. But as they handle books in foreign languages, they gradually acquire a feeling for words as they are used on the title page and elsewhere in the books, and come to recognize them as nouns, parts of corporate bodies, etc. With the use of a dictionary and the following table, the problem of capitalization can be reduced considerably. Although the knowledge of proper capitalization is certainly a prime concern when preparing a master or unit card, it is not restricted to the catalog 
department. Other departments within a library can find use for this table.

The table does not profess to answer every question on capitalization or to give complete coverage. It is offered merely as a help, a quick-glance reference, for those who care that their catalog cards and records appear with correct capitalization.

\section{CAPITALIZATION}

\section{(Brief guidelines)}

Language

GROUP 1

(full cap.)

English

Spanish

Portuguese $\mathrm{X}$

Polish

Dutch

German

Greek

Latin

GROUP 2

(little cap.

French

Slavic

Italian

Scandinavian

Icelandic

\section{Proper \\ nouns \\ Proper adjs.}

Corporate bodies

All major words
All

Only 1st

\& 1st of

each sect.
Days \& months

Scientific names of families are given in Latin, no matter what the language of the book. The first word (genus) is capitalized; the second word (species) if given, is not capitalized.

IN GENERAL:

Capitalize only the first word of a title.

Capitalize only the first word of a periodical or series (as Journal of linguistic studies) or the first word after an initial article (as The Journal of Biblical studies)

CONSULT the Anglo-American Catalog Code for specific cases or possible exceptions.

CAUTION: Do not abide by old L. C. practice (prior to 1949) when consulting NUC's. Rules for capitalization changed in 1949.

This also applies to any library catalog, where old practice appears along with current practice.

( $X$ indicates capitalization of word) 